DP -1759

DE89 001169

\title{
SOLVENT DEGRADATION PRODUCTS \\ IN NUCLEAR FUEL PROCESSING SOLVENTS
}

\author{
H. E. Shook, Jr.
}

Publication Date: June 1988

\section{Approved by:}

\section{DISCLAIMER}

This report was prepared as an account of work sponsored by an agency of the United States Government. Neither the United States Government nor any agency thereof, nor any of their employees, makes any warranty, express or implied, or assumes any legal liability or responsibility for the accuracy, completeness, or usefulness of any information, apparatus, product, or process disclosed, or represents that its use would not infringe privately owned rights. Reference herein to any specific commercial product, process, or service by trade name, trademark, manufacturer, or otherwise does not necessarily constitute or imply its endorsement, recommendation, or favoring by the United States Government or any agency thereof. The views and opinions of authors expressed herein do not necessarily state or reflect those of the United States Government or any agency thereof.

\section{E. W. Holtzschelter, Research Manager Actinide Technology Division}

\section{E. It du Pont de Nemours \& Co. Savannah River Laboratory Alken, SC 29808}




\section{DISCLAIMER}

This report was prepared as an account of work sponsored by an agency of the United States Government. Neither the United States Government nor any agency Thereof, nor any of their employees, makes any warranty, express or implied, or assumes any legal liability or responsibility for the accuracy, completeness, or usefulness of any information, apparatus, product, or process disclosed, or represents that its use would not infringe privately owned rights. Reference herein to any specific commercial product, process, or service by trade name, trademark, manufacturer, or otherwise does not necessarily constitute or imply its endorsement, recommendation, or favoring by the United States Government or any agency thereof. The views and opinions of authors expressed herein do not necessarily state or reflect those of the United States Government or any agency thereof. 


\section{DISCLAIMER}

Portions of this document may be illegible in electronic image products. Images are produced from the best available original document. 


\section{ABSTRACT}

The Savannah River Plant uses a modified Purex process to recover enriched uranium and separate fission products. This process uses $7.5 \%$ tri-n-butyl phosphate (TBP) dissolved in normal paraffin hydrocarbons for the solvent extraction of a nitric acid solution containing the materials to be separated. Periodic problems in product decontamination result from solvent degradation. A study to improve process efficiency has identified certain solvent degradation products and suggested mitigation measures.

Undecanoic acid, lauric acid, and tridecanoic acid were tentatively identified as diluent degradation products in recycle solvent. These long-chain organic acids affect phase separation and lead to low decontamination factors. Solid phase extraction (SPE) was used to concentrate the organic acids in solvent prior to analysis by high performance liquid chromatography (HPLC). SPE and HPLC methods were optimized in this work for analysis of decanoic acid, undecanoic acid, and lauric acid in solvent.

Accelerated solvent degradation studies with $7.5 \%$ TBP in normal parafin hydrocarbons showed that long-chain organic acids and long-chain alkyl butyl phosphoric acids are formed by reactions with nitric acid. Degradation of both tributyl phosphate and hydrocarbon can be minimized with purified normal paraffin replacing the standard grade presently used. 


\section{Page}

INTRODUCTION

$\begin{array}{ll}\text { SUMMARY } & 5\end{array}$

DISCUSSION 16

Purex Process Description 6

HM Process Description $\quad 7$

$\begin{array}{ll}\text { Solvent Degradation } & 7\end{array}$

Laboratory Studies $\quad 8$

Solid Phase Extraction $\quad 8$

Accelerated Solvent Degradation Studies 10

Solvent Effects 11

CONCLUSIONS 11

ACKNOWLEDGEMENT

REFERENCES 


\section{LIST OF TABLES}

Page

1. Paraffin Compositions

2. Long-Chain Organic Acids from Accelerated

Solvent Degradation Studies with 7.5\% TBP/Hydrocarbons

3. Characterization of Degraded 7.5\% TBP/Hydrocarbons

\section{LIST OF FIGURES}

1. Purex Process 


\section{INTRODUCTION}

The Savannah River Plant (SRP) uses the Purex process to recover and purify plutonium and uranium from irradiated natural or depleted uranium nuclear targets. 1 The process is a countercurrent solvent extraction process in which 30 volume \% tri-n-butyl phosphate (TBP) dissolved in normal paraffin hydrocarbons (NPH) is used to extract uranium and plutonium from an aqueous nitric acid solution. In a modified (HM) process developed by the Savannah River Laboratory, SRP uses 7.5 volume \% TBP/NPH to process and recover uranium fuels containing ${ }^{235} \mathrm{U}$ at enrichments from $1.1 \%$ to $94 \% .2$ Over the years, serious problems with solvent degradation have occurred in both processes. $1,2,3$

The solvent is degraded during contact with nitric acid and radiation in the solvent extraction process. As it is being recycled, it is cleaned with continuous solvent washes of alternating sodium carbonate solution and nitric acid. Nevertheless, certain degradation products not completely removed by this washing process accumulate to cause aqueous/organic emulsions and fission product retention. As a result, product losses and decontamination factors with recycle solvent in both SRP processes are worse than those with new solvent by factors of 5 to 20.1 Shorter allowable periods of continuous processing and longer solvent washing times are required to assure acceptable product.

A goal for the SRP HM process has been to increase its ability to process highly active fuels and to extend its ability for continuous operation. Improved solvent cleaning technology was judged essential in achieving this goal. Extended carbonate washing removed residual radioactivity from the solvent, but solvent degradation products affecting interfacial tension and zirconium pickup were not removed. The solvent has been cleaned effectively by passing it through a bed of alumina in the recycle line. ${ }^{4}$ In parallel work reported here, we have attempted to identify the offending degradation products and prevent their formation.

\section{SUMMARY}

Undecanoic $\left(C_{11}\right)$ acid, lauric $\left(C_{12}\right)$ acid, and tridecanoic $\left(C_{13}\right)$ acid were tentatively identified as diluent degradation products in first cycle $\mathrm{HM}$ process solvent prior to a fullscale cleanup with alumina. These long-chain organic acids affect phase separation and lead to low decontamination factors. Solid phase extraction (SPE) was used to concentrate the organic acids in solvent prior to analysis by high performance liquid chromatography (HPLC). SPE and HPLC methods were optimized in this work for analysis of decanoic $\left(C_{10}\right)$ acid, $C_{11}$ acid, and $C_{12}$ acid in solvent.

Accelerated solvent degradation studies with 7.5\% TBP/NPH showed that longchain organic acids and long-chain alkyl butyl phosphoric acids are formed by reactions with 10M nitric acid. The long-chain organic acids are known to affect phase separation at low concentrations, and the butyl phosphoric acids from TBP are known to be binding 
ligands for zirconium. $2,5,6,7$ Reduced extraction stage efficiencies and the presence of binding ligands combine to reduce the fission product decontamination factor. In general, higher concentrations of organic acids and long-chain alkyl butyl phosphoric acids are produced as the reaction time is increased.

Degradation of both TBP and NPH can be minimized with purified normal paraffin replacing the standard grade NPH presently used. Purified normal paraffins are now commercially available due to their demand by producers of chloroparaffins and biodegradable detergents. If the standard grade paraffin were replaced, the higher cost for purified paraffin in SRP might be more than offset by savings in the reduced quantity of TBP purchased. The time interval between solvent cleaning with alumina may also be increased.

\section{DISCUSSION}

\section{Purex Process Description}

The major operations of SRP's Purex process are shown in Figure 1. The aluminum jackets of the irradiated target slugs are dissolved in sodium hydroxide and sodium nitrate. The dejacketed slugs are dissolved in nitric acid. The dissolver solution is clarified in Head End to remove silica.

Typical Purex feed contains uranyl nitrate, plutonium nitrate, nitric acid, and fission and neutron activation products. In the first solvent extraction cycle, uranium and plutonium are separated from fission products in an 18-stage centrifugal contactor by extraction into $30 \%$ TBP/NPH solvent.

Typical NPH compositions are shown in Table 1. A purified normal paraffin available from EniChem Americas is also shown in Table 1. Most of the fission products stay with the aqueous phase which is transferred to high-activity waste evaporator.

The solvent from the $1 \mathrm{~A}$ contactor is transferred to mixer-settler 1B. Plutonium is reduced to Pu(III) valence and is stripped into the aqueous $1 \mathrm{BP}$ stream. This is sent to the second plutonium solvent extraction cycle. Uranium dissolved in the solvent is fed to mixer-settler 1C. Uranium is stripped from the solvent into stream $1 \mathrm{CU}$ with dilute nitric acid.

The aqueous 1CU stream is concentrated in an evaporator before going to the second uranium solvent extraction cycle. The uranium is decontaminated further from plutonium and fission products by extracting it into solvent in mixer-settler 1D. The uranium is stripped from the solvent into stream $1 E U$ in mixer-settler $1 E$.

In the second plutonium solvent extraction cycle, plutonium is decontaminated further from fission products by extracting it into solvent in mixer-settler 2A. Plutonium is stripped from the solvent in mixer-settler $2 \mathrm{~B}$. The aqueous plutonium product solution, $2 \mathrm{BP}$, is transferred to the plutonium finishing line.

Rather than the 18-stage centrifugal contactor described above, the original SRP Purex process had a small 1A 16-stage mixer-settler bank ${ }^{3}$ This was later replaced with a 24-stage bank in 1959. The many long-residence stages gave excellent decontamination factors for zirconium and ruthenium. However, long residence times caused serious 
solvent degradation problems. A low, but stable, decontamination was provided by improved solvent washing, dodecane diluent, and limitations on feed activity. Solvent degradation and decontamination were improved somewhat in 1966 by replacing the mixersettler bank with an 18-stage centrifugal contactor.

\section{HM Process Description}

Uranium fuels containing $235 \mathrm{U}$ are processed and recovered, along with neptunium and plutonium byproducts, in the HM process at SRP. ${ }^{2}$ Aluminum-clad fuels are dissolved in nitric acid. Fuels clad in more resistant materials are dissolved in an electrolytic dissolver. Uranium, neptunium, and plutonium are separated from fission products and from one another by multistage countercurrent solvent extraction, using mixer-settlers, with $7.5 \%$ TBP/NPH. The enriched uranium is recovered as a dilute solution and shipped offsite for further processing.

The solvent extraction process uses a first cycle for primary decontamination and separation, and two second cycles for final decontamination. One second cycle is for uranium, and the other is for neptunium or plutonium. In each cycle, the actinides are extracted from an aqueous feed stream into an immiscible organic solvent. The product is stripped back into an aqueous stream. Separate solvent inventories are maintained for each cycle. In a solvent recovery process, the solvent is washed continuously with sodium carbonate to remove most of the radioactive contami- nants and degradation products. The solvent is treated with nitric acid to neutralize any residual alkalinity, and then the solvent is reused.

During 1985, the uranium product had to be recycled through the second solvent extraction cycle because the zirconium-95 concentration was too high. ${ }^{4}$ In early 1986 , problems with decontamination from ruthenium-106 were experienced. Examination of historical data showed that the first solvent extraction cycle suffered a dramatic decrease in the zirconium decontamination factor (DF) in mid-1984. The process remained at the lower DF after this time.

Laboratory work to improve first cycle DF suggested that the plant recycle solvent quality had deteriorated. A higher DF could be obtained with new solvent. Gamma activity analysis of first cycle solvent after washing showed that it contained a high residual activity. Improved solvent cleaning technology was judged essential in improving solvent quality.

Extended carbonate washing removed residual radioactivity from the solvent, but solvent degradation products affecting interfacial tension and zirconium pickup were not removed. The solvent has been cleaned effectively by passing it through a bed of alumina in the recycle line. 4 In parallel work reported here, we have attempted to identify the offending degradation products and prevent their formation.

\section{Solvent Degradation}

A mixture of TBP and NPH diluent is used in processing reactor fuel and target elements. The solvent is degraded during contact with nitric acid and radiation in the first cycle of the solvent extraction process. The solvent is normally cleaned with continuous solvent washes of altemating sodium carbonate solution and nitric acid and recycled. 
The sodium carbonate solvent wash is applied to remove dibutyl phosphoric acid (DBP) and monobutyl phosphoric acid (MBP), degradation products of TBP.8 DBP forms strong complexes with zirconium, uranium(VI), and plutonium(IV) and extracts them into the organic phase. ${ }^{2}$ Some zirconium is released to the aqueous product streams, restricting decontamination. Retained zirconium in recycle solvent causes undesirable radiation in solvent storage.

Accelerated solvent degradation studies have been performed at Oak Ridge National Laboratory with $30 \%$ TBPNPH.5 Spectrophotometric, gas chromato-graphic, mass spectrographic, and titrimetric methods were used to identify alkane nitro and nitrate compounds, alcohols, unsaturated alcohols, nitro alcohols, nitro alkenes, ketones, and organic acids in the solvent. Long-chain organic acids were detected by potentiometric titration and infrared spectral analyses. Long-chain alkyl butyl phosphoric acids have been reported by other workers. ${ }^{7}$ These are known to be binding ligands for zirconium. Longchain organic acids in SRP solvent are potentially serious degradation products because of their effect on phase separation at concentrations as low as $1 \times 10^{-3} \mathrm{M}$. The effect of $C_{12}$ acid in solvent on interfacial tension has been studied. ${ }^{4,5}$ The interfacial tension starts to decrease around $1 \times 10^{-5} \mathrm{M} \mathrm{C}_{12}$ acid concentration. The long-chain organic acid content of SRP Purex solvent was found to be about $1.3 \times 10^{-3} \mathrm{M}^{5}$

A potentiometric titration technique has been developed to analyze mixtures of di (2-ethylhexyl) and mono (2-ethylhexyl) phosphoric acids." We used this analytical method to analyze mixtures of MBP/DBP with $\mathrm{C}_{12}$ acid and found that the second acidic proton of MBP titrates at the same time as the acidic proton of $\mathrm{C}_{12}$ acid. Acids in $\mathrm{HM}$ process solvent were not detected with this analytical method. Therefore, we developed solid phase extraction (SPE) methods to concentrate the organic acids in solvent prior to analysis by high performance liquid chromatography (HPLC).

\section{Laboratory Studies}

\section{Solid Phase Extraction}

Since SRP NPH is primarily tridecane (Table 1), a standard solution containing tridecanoic $\left(\mathrm{C}_{13}\right)$ acid in $7.5 \%$ TBP/NPH was prepared to test columns obtained from J. T. Baker Chemical Co. ${ }^{10}$ The disposable columns are polypropylene tubes prepacked with adsorbent particles ( $1000 \mathrm{mg}$ sorbent) contained by two polyethylene frits with $20 \mu \mathrm{m}$ pores. Kieselguhr, silica gel, FlorisilO, and alumina (neutral) were tested using the same SPE condicions. Only a trace of $\mathrm{C}_{13}$ acid was recovered from kieselguhr and silica gel using methanol elution. These columns do not surongly adsorb $\mathrm{C}_{13}$ acid in the presence of the competing TBP. None of the $\mathrm{C}_{13}$ acid was recovered from alumina. The alumina adsorbed all of the $C_{13}$ acid, but methanol did not elute it. This was confirmed by treating a $7.5 \%$ TBP/hexane solution containing $C_{13}$ acid with an alumina column. Hexane was evaporated from the collected product, and the residue was dissolved in methanol for HPLC analysis. No trace of $C_{13}$ acid was detected. All acid had been adsorbed by the alumina. Recovery of $\mathrm{C}_{13}$ acid from alumina by elution with acetic acid was very erratic. Recoveries varied from $<50 \%$ to $89 \%$. 
Good results were obtained with Florisil(2) columns. In order to determine the recovery factor of $\mathrm{C}_{13}$ acid, we prepared a standard $7.5 \%$ TBP/NPH solution containing $282 \mathrm{ppm} \mathrm{C}_{13}$ acid. In ten tries with Baker Florisilo columns (1000 mg sorbent), the mean recovery of $\mathrm{C}_{13}$ acid was $91 \pm 3 \%$. The adsorbed acid was eluted from Florisile with methanol.

Quantities of first cycle SRP HM process solvent, obtained prior to the full-scale cleanup of the entire first cycle solvent inventory with activated alumina, were passed through Fisher adsorption alumina. Material adsorbed on the column was eluted with large fractions of methanol. Each fraction was concentrated and then examined by HPLC. The analysis was run on a Hewlett-Packard 1090A Liquid Chromatograph with a Hypersil ODS, 5-micron column, $200 \times 2.1 \mathrm{~mm}$ ID. The mobile phase was $90 \%$ methanol/10\% $\left(\mathrm{H}_{3} \mathrm{PO}_{4}, 1 \%\right)$, and the flow rate was $0.5 \mathrm{ml} / \mathrm{minute}$. We used a photo-diode array for detection. The detector allows the collection of spectrum at wavelengths from 190 to $600 \mathrm{~nm}$ for each compound separated by the column. The first fraction showed chromatographic peaks at $1.89,2.09,2.24,2.52$, and 2.70 minutes. The compounds eluting at $1.89,2.24$, and 2.70 minutes had retention times closely matching those for $C_{11}$ acid, $\mathrm{C}_{12}$ acid, and $\mathrm{C}_{13}$ acid, respectively, from a standard. The spectrum for the peak at 2.70 minutes matched that for $C_{13}$ acid with maximum absorption at 200-220 nm. The other eluting compounds were not pure. Each had varying amounts of material with an absorption at 290-300 nm. All of the compounds had the characteristic uv absorption for a carboxylic acid. The other fractions recovered from the alumina column did not show any peaks eluting in the region where long-chain acids elute. Thus, $C_{11}$ acid, $C_{12}$ acid, and $\mathrm{C}_{13}$ acid were tentatively identified in first cycle $\mathrm{HM}$ process solvent prior to the full-scale cleanup with alumina.

Since trace amounts of strongly uv-absorbing material elute with the long-chain organic acids, we used a less sensitive refractive index detector for the HPLC analysis. The SPE method uses $6 \mathrm{ml}$ Florisil@ columns (1000 mg sorbent). The disposable columns are polypropylene tubes prepacked with Florisile $\left(\mathrm{SiO}_{\mathrm{n}}\right)$ particles contained by two polyethylene frits with $20 \mu \mathrm{m}$ pores.

The column is attached to a vacuum manifold. The column is conditioned by aspirating $6 \mathrm{ml}$ tetrahydrofuran (THF) through the column. The column must not be allowed to dry. Five mil of the 7.5\% TBP/NPH solvent is slowly passed through the column over a 10-minute period. The column is washed with 3 aliquots ( 2 ml each) THF to remove interfering material such as TBP and dried for 5 minutes by aspirating air. The column is then eluted with 3 aliquots $(800 \mu l$ each) methanol to recover the organic acids. The product is adjusted to $1 \mathrm{ml}$ for HPLC analysis. The concentration factor is 5 , and the concentration of the recovered acid is multiplied by the ratio of the density of methanol to the density of 7.5\% TBP/NPH to convert to concentration in 7.5\% TBP/NPH. In six tries, the mean recoveries of $\mathrm{C}_{10}$ acid and $\mathrm{C}_{11}$ acid from a standard 7.5\% TBP/NPH solution were $91 \pm 4 \%$ and $95 \pm 4 \%$, respectively. The standard contained 287 ppm $C_{10}$ acid and 303 ppm $C_{11}$ acid. In six tries, the mean recoveries of $C_{10}$ acid, $C_{11}$ acid, and $C_{12}$ acid from a standard $30 \%$ TBP/NPH solution were $96 \pm 3 \%, 87 \pm 5 \%$, and $85 \pm 4 \%$, respectively. The standard contained $117 \mathrm{ppm}$ nonanoic ( $\left.C_{9}\right)$ acid, $220 \mathrm{ppm} \mathrm{C}_{10}$ acid, 248 ppm $C_{11}$ acid, and 222 ppm $C_{12}$ acid.

The HPLC analysis is run on a Hewlett-Packard 1090A Liquid Chromatograph with an Alltech Adsorbosphere HSC 18,5-micron column, $150 \times 2$ mm ID. The mobile phase is $72 \%$ methanol/28\% water. An Alltech ion-pair chromatography reagent, 
tetrabutylammonium phosphate, is added to the mobile phase to give a concentration of $0.005 \mathrm{M}$. Flow rate $=0.4 \mathrm{ml} / \mathrm{minute}$. Detection is with a Hewlett-Packard $1037 \mathrm{~A}$ Refractive Index Detector. At these conditions, acids with fewer than ten carbon atoms are not retained by the column.

\section{Accelerated Solvent Degradation Studies}

Accelerated solvent degradation studies were performed to learn what long-chain organic acids would be produced from mixtures of TBP with saturated aliphatic hydrocarbons. $C_{11}$ acid, $C_{12}$ acid, and $C_{13}$ acid had been identified in $H M$ process solvent prior to cleaning with alumina.

For these studies, $25 \mathrm{ml} 10 \mathrm{M}$ nitric acid was mixed with $25 \mathrm{ml} 7.5 \%$ TBP/NPH and 0.1 gram sodium nitrite in a flat bottom flask on a hot plate. The flask was fitted with an air condenser, and the mixture was stirred with a magnet at reflux temperature. The cooled mixture was separated, and the organic phase was washed three times with 25 ml each water. The organic phase was centrifuged to remove traces of water.

Organic phases from the reactions were analyzed for organic acids, TBP, fission product pickup, ${ }^{4}$ and interfacial tension. ${ }^{4}$ Organic phases were washed with a sodium carbonate solution to remove DBP and MBP prior to the fission product pickup analysis.

Surprisingly, both TBP and hydrocarbon degradation can be minimized with purified normal paraffin. Analyses for long-chain organic acids are shown in Table 2, and analyses for TBP, fission product pickup, and interfacial tension are presented in Table 3 . The organic acids tend to increase in concentration as the reaction time is increased. Long-chain organic acids can convert to shorter-chain acids by oxidation and loss of carbon as carbon dioxide. With $99+\%$ tridecane (Table 2), long-chain organic acids were not detected after 2 1-hour reaction. With $99+\%$ dodecane, only a trace of $\mathrm{C}_{10}$ acid was detected, while SRP NPH gave $101 \mathrm{ppm} \mathrm{C}_{10}$ and $101 \mathrm{ppm} \mathrm{C}_{11}$ acids. The interfacial tension remained high after 1 -hour reactions with $99+\%$ tridecane and $99+\%$ dodecane (Table 3 ). The higher the interfacial tension, the faster the solvent separates from the aqueous phase. The interfacial tension was drastically reduced with SRP NPH. The lowest Zr-95 pickups were obtained after 1-hour reactions with purified tridecane and dodecane. $\mathrm{Z}-95$ pickup increases as the reaction time is increased. Compared to a 1-hour reaction with SRP NPH, lower Ru-106 pickups were obtained with purified tridecane and dodecane. However, there was no trend to increasing Ru-106 pickup as reaction time increased. The TBP concentrations remained high with purified tridecane and dodecane. TBP concentration was reduced from $7.5 \%$ to about $5 \%$ with SRP NPH

In earlier accelerated solvent degradation studies with $30 \%$ TBP/hydrocarbons, analyses for TBP were not reported.5,11 There is no mention that TBP degradation is minimized by mixing it with purified normal paraffin. A very thorough search for a highlystable diluent for the SRP Purex process was conducted because there was an incentive to reduce solvent recycle problems to a minimum. ${ }^{11}$ Forty-nine commercially available hydrocarbon products were studied. Stability was judged by testing for zirconium retention after chemical or radiolytic degradation. A diluent composed of normal parafins and free of olefins and aromatics was preferred. 
Purified normal paraffin is commercially available for testing as a diluent in nuclear fuel processing solvents. Dearomatized types with 0.07-0.08 wt \% aromatics can be obtained. The normal type has 0.3-0.4 wt \% aromatics. Sulfur and bromine are considerably reduced with the dearomatized type.

\section{Solvent Effects}

Butyl phosphoric acids are zirconium binding ligands. 26.7 Butyl lauryl phosphoric acid has been studied as a model compound for long-chain alkyl butyl phosphoric acids. ${ }^{6}$ It does not cause retention of ruthenium in solvent. It is able to complex zirconium, and its behavior is similar to dibutyl phosphoric acid. The threshold concentration for enhancement of zirconium extraction with a Purex solvent is $2 \times 10^{-4} \mathrm{M}$. This concentration should be even lower with HM process solvent where the TBP concentration is only $7.5 \%$.

Addition of $\mathrm{C}_{12}$ acid to TBP/paraffin solvent reduces the solvent's interfacial tension. ${ }^{4}$ Pickup tests on solvent with $2 \times 10^{-3}$ to $2 \times 10^{-5} \mathrm{M}$ lauric acid show that longchain organic acids do not cause retention of zirconium or ruthenium. ${ }^{12}$ Long-chain organic acids in SRP solvent are potentially serious degradation products because of their effect on phase separation at concentrations as low as $1 \times 10^{-3} \mathrm{M} .{ }^{5}$

Analyses of organic phases from accelerated solvent degradation studies with $7.5 \%$ TBP/NPH show that long-chain organic acids and long-chain alkyl butyl phosphoric acids are formed. The long-chain organic acids reduce the interfacial tension of the solvent. The chemical structures of long-chain alkyl butyl phosphoric acids suggests that they too reduce the solvent's interfacial tension. The long-chain alkyl butyl phosphoric acids also cause zirconium retention in the recycle solvent. Reduced extraction stage efficiencies and the presence of binding ligands combine to reduce the fission product decontamination factor.

Long-chain organic acids and long-chain alkyl butyl phosphoric acids, unlike monobutyl and dibutyl phosphoric acids, cannot be removed from solvent with a carbonate wash. Their concentration in recycle solvent increases until a secondary cleanup method is used. These degradation products are effectively extracted from solvent with alumina.

\section{CONCLUSIONS}

Long-chain organic acids were tentatively identified in first cycle HM process solvent prior to cleaning with alumina. The zirconium retention behavior of the solvent suggests that long-chain alkyl butyl phosphoric acids were also present. Therefore, these degradation products were responsible for the emulsion and zirconium retention problems observed with HM process solvent prior to solvent cleaning with alumina.

Accelerated degradation studies with mixtures of TBP and saturated aliphatic hydrocarbons show that both TBP and hydrocarbon degradation can be minimized with purified normal paraffin. The degradation reactions produce long-chain organic acids and long-chain alkyl butyl phosphoric acids. Purified normal paraffin is commercially 
available for testing as a diluent in nuclear fuel processing solvents. If the standard grade paraffin were replaced, the higher cost for purified paraffin in SRP might be more than offset by savings in the reduced quantity of TBP purchased. The time interval between solvent cleaning with alumina may also be increased.

\section{ACKNOWLEDGEMENT}

Many thanks to D. J. Reif, Savannah River Laboratory, for help with sample preparation for the Zr-95 pickup test.

\section{REFERENCES}

1. McKibben, J. M., "Chemistry of the Purex Process," Radiochemica Acta 36, 3-15 (1984).

2. Hyder, M. L., et al., Processing of Irradiated Enriched Uranium Fuels at the Savannah River Plant, U. S. DOE Report DP-1500, E. I. du Pont de Nemours \& Company, Savannah River Laboratory, Aiken, South Carolina (1979).

3. Orth, D. A., Purex: Process and Equipment Performance, DP-MS-86-28, E. I. du Pont de Nemours \& Company, Savannah River Laboratory, Aiken, South Carolina (1986).

4. Reif, D. J., Cleanup of $7.5 \%$ Triburyl Phosphate/N-Paraffin Solvent-Extraction Solven: U. S. DOE Report DP-1735, E. I. du Pont de Nemours \& Company, Savannah River Laboratory, Aiken, South Carolina (1987).

5. Tallent, O. K., Mailen, J. C., and Pannell, K. D., Purex Diluent Degradation, ORNL/TM-8814 (1984).

6. Maya, L., and Bopp, C. D., L. Inorg Nucl Chem 40,1147 (1978).

7. Becker, R., and Stieglitz, L., Kernforschungszentrum Karlsruhe Report KFK 1373 (1973).

8. Dukes, E. K., The Formation and Effects of Dibutyl Phosphate in Solvent Extraction, U. S. DOE Report DP-250, E. I. du Pont de Nemours \& Company, Savannah River Laboratory, Aiken, South Carolina (1957).

9. DEHPA Extractan, Bulletin No. 081201, Albright and Wilson, Inc., Post Office Box 26229, Richmond, Virginia 23260-6229.

10. 'Baker'-10 SPE Applications Guide, Volume 1, J. T. Baker Chemical Co., 222 Red School Lane, Phillipsburg, New Jersey.

11. Dennis, B. P., and West, D. L., Evaluation of Hydrocarbon Diluents for the Purex Process, U. S. DOE Report DP-671, E. I. du Pont de Nemours \& Company, Savannah River Laboratory, Aiken, South Carolina (1961).

12. Reif, D. J., Savannah River Laboratory, Aiken, South Carolina, Private Communication. 
Table 1

Parafin Compositions Wt \%

\begin{tabular}{|c|c|c|c|c|}
\hline & Conoco & Texaco & $\begin{array}{c}\text { Cole } \\
\text { Chemical }\end{array}$ & $\begin{array}{l}\text { EniChem } \\
\text { Americas }\end{array}$ \\
\hline \multicolumn{5}{|l|}{ Paraffin Homologs } \\
\hline $\mathrm{C}_{11}$ & 0.5 & 0.5 & 0.5 & 1.5 \\
\hline $\mathrm{C}_{12}$ & 15.3 & 11.1 & 11.3 & 13 \\
\hline $\mathrm{C}_{13}$ & 51.4 & 49.0 & 56.6 & 55.7 \\
\hline $\mathrm{C}_{14}$ & 25.7 & 37.5 & 31.4 & 27.4 \\
\hline $\mathrm{C}_{15}$ & 6.0 & 1.9 & 0.8 & $<2$ \\
\hline $\mathrm{C}_{16}$ & 1.1 & - & - & \\
\hline Branched Cycloparaffins & & 0.8 & 1.1 & \\
\hline \multicolumn{5}{|l|}{ Aromatic Homologs } \\
\hline Tetralins and Indanes & & 0.03 & 0.7 & \\
\hline Naphthalenes & & 0.07 & 0.2 & \\
\hline Alkylbenzenes & & 0.06 & 0.2 & \\
\hline Biphenyls & & 0.003 & 0.05 & \\
\hline Total Aromatics & 0.8 & 0.6 & 1.7 & 0.07 \\
\hline Total Olefins & 0.06 & 0.16 & 0.15 & \\
\hline
\end{tabular}


Table 2

Long-Chain Organic Acids from Accelerated

Solvent Degradation Studies with 7.5\% TBP/Hydrocarbons

Diluent

SRP NPH

SRP NPH

SRP NPH

Dodecane, $99+\%$

Dodecane, $99+\%$

Tridecane, $99+\%$

Tridecane, $99+\%$

Tetradecane, $99 \%$

Tetradecane, $99 \%$
Reaction

Time. hrs.

1

3

4

$\frac{1}{2}$

1

2

1
Organic Acids

\begin{tabular}{|c|c|c|}
\hline $\begin{array}{l}\mathrm{C}_{10} \\
\text { pom }\end{array}$ & $\begin{array}{l}\mathrm{C}_{11} \\
\text { ppm }\end{array}$ & $\begin{array}{l}\mathrm{C}_{12} \\
\text { ppm }\end{array}$ \\
\hline $\begin{array}{l}101 \\
224 \\
142\end{array}$ & $\begin{array}{l}101 \\
294 \\
188\end{array}$ & $\begin{array}{l}\text { Detected } \\
128 \\
\text { Detected }\end{array}$ \\
\hline $\begin{array}{l}\text { Detected } \\
274\end{array}$ & $\begin{array}{l}\text { Not Detected } \\
\text { Detected }\end{array}$ & $\begin{array}{l}\text { Not Detected } \\
\text { Not Detected }\end{array}$ \\
\hline $\begin{array}{l}\text { Not Detected } \\
200\end{array}$ & $\begin{array}{l}\text { Not Detected } \\
491\end{array}$ & $\begin{array}{l}\text { Not Detected } \\
\text { Detected }\end{array}$ \\
\hline $\begin{array}{l}115 \\
182\end{array}$ & $\begin{array}{l}\text { Detected } \\
187\end{array}$ & $\begin{array}{l}\text { Detected } \\
291\end{array}$ \\
\hline
\end{tabular}




\section{Table 3}

\section{Characterization of Degraded 7.5\% TBP/Hydrocarbons}

\begin{tabular}{|c|c|c|c|c|c|}
\hline Diluent & $\begin{array}{l}\text { Reaction } \\
\text { Time, hrs. }\end{array}$ & $\begin{array}{c}\text { TBP } \\
\mathscr{0} \\
\end{array}$ & $\begin{array}{r}\text { Pi } \\
\mathrm{d} / \mathrm{m} / \mathrm{n} \\
\mathrm{Ru}-106 \\
\end{array}$ & $0^{3}$ & $\begin{array}{c}\text { Interfacial } \\
\text { Tension } \\
\text { dynes/cm }\end{array}$ \\
\hline $\begin{array}{l}\text { SRP NPH } \\
\text { SRP NPH } \\
\text { SRP NPH } \\
\text { SRP NPH }\end{array}$ & $\begin{array}{l}0 \\
1 \\
3 \\
4\end{array}$ & $\begin{array}{l}7.5 \\
5.1 \\
5.1 \\
5.1\end{array}$ & $\begin{array}{c}9.5 \\
15.1 \\
0 \\
0\end{array}$ & $\begin{array}{c}0 \\
39.1 \\
168.2 \\
173.0\end{array}$ & $\begin{array}{r}13.0 \\
<2.7 \\
<2.7 \\
<2.7\end{array}$ \\
\hline $\begin{array}{l}\text { Dodecane, } 99+\% \\
\text { Dodecane, } 99+\%\end{array}$ & $\frac{1}{2}$ & $\begin{array}{l}7.0 \\
6.0\end{array}$ & $\begin{array}{l}6.4 \\
6.2\end{array}$ & $\begin{array}{r}21.0 \\
171.8\end{array}$ & $\begin{array}{r}12.9 \\
<2.7\end{array}$ \\
\hline $\begin{array}{l}\text { Tridecane, } 99+\% \\
\text { Tridecane, } 99+\%\end{array}$ & $\frac{1}{2}$ & $\begin{array}{l}6.6 \\
6.7\end{array}$ & $\begin{array}{c}12.6 \\
0\end{array}$ & $\begin{array}{r}1.6 \\
97.5\end{array}$ & $\begin{array}{r}13.3 \\
<2.7\end{array}$ \\
\hline $\begin{array}{l}\text { Tetradecane, } 99 \% \\
\text { Tetradecane, } 99 \%\end{array}$ & $\frac{1}{2}$ & $\begin{array}{l}4.8 \\
3.9\end{array}$ & $\begin{array}{c}22.4 \\
0\end{array}$ & $\begin{array}{r}87.7 \\
260.0\end{array}$ & $\begin{array}{l}<2.7 \\
<2.7\end{array}$ \\
\hline
\end{tabular}

aFor pickup tests, all solutions were adjusted to 7.5\% TBP. 


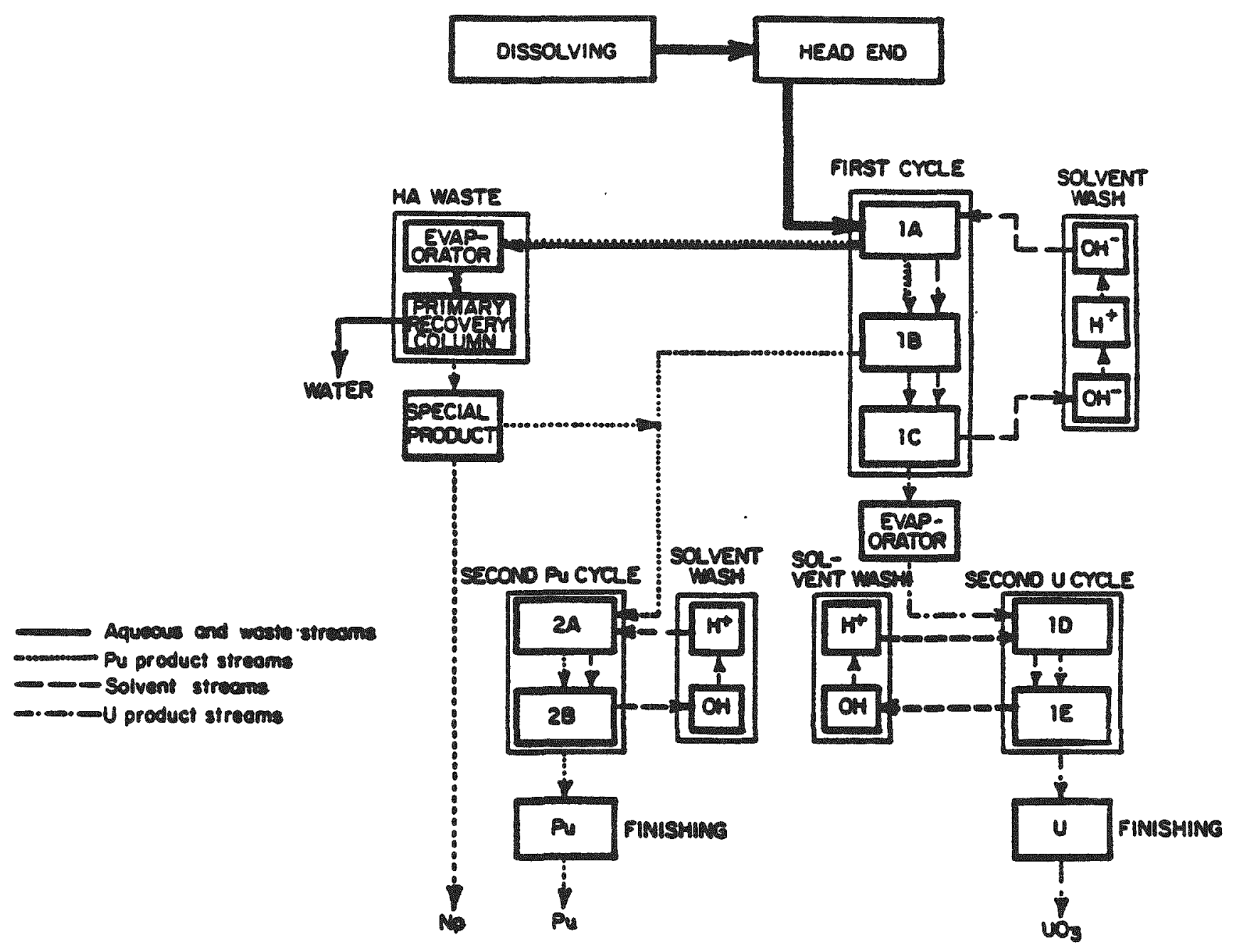

FIGURE 1. Purex Process 


\section{DISTRIBUTION}

\section{1-3. J. R. Powell, DOE-SR}

4-44. SRL File, 773-A

45-120. DOE OSTI-TIC (for distribution under UC-711) 